\title{
Lingkungan Kerja Sosial Dan Pengembangan Karir Sebagai Pengaruh Kepuasan Kerja Karyawan
}

\author{
N. Maharani, Sumiyati \& Masharyono \\ Universitas Pendidikan Indonesia \\ nadia.maharani@student.upi.edu
}

\begin{abstract}
The purpose of this research was to see how much influence the social work environment and career development had on employee job satisfaction. Type of Research Methodology used is descriptive verification. The method used is explanatory survey with simple random sampling technique and the number of samples is 102 respondents. The data analysis technique used is multiple linear regression with SPSS 21.0 computer software tools. The findings based on the results of the study can be seen that simultaneously or partially the social work environment and career development can improve employee job satisfaction. The difference in this study lies in the research object, research time, measuring instruments, literature used, the theory used and the results of the study.

\begin{tabular}{l}
\hline ABSTRAK \\
Tujuan Penelitian ini dilaksanakan untuk melihat seberapa besar \\
pengaruh lingkungan kerja sosial dan pengembangan karir terhadap \\
kepuasan kerja karyawan. Jenis Metodologi Penelitian yang digunakan \\
adalah deskriptif verifikatif. Metode yang digunakan adalah explanatory \\
survey dengan teknik simple random sampling dan jumlah sampel \\
adalah 102 responden.Teknik analisis data yang digunakan adalah \\
regresi linier berganda dengan alat bantu software komputer SPSS 21.0 . \\
Temuan berdasarkan hasil penelitian dapat diketahui bahwa secara \\
simultan maupun parsial lingkungan kerja sosial dan pengembangan \\
karir dapat meningkatkan kepuasan kerja karyawan. Perbedaan dalam \\
penelitian ini terletak pada objek peneltian, waktu penelitian, alat ukur, \\
literatur yang digunakan, teori yang digunakan dan hasil penelitian.
\end{tabular}
\end{abstract}

\section{ARTICLE INFO: \\ Article history: \\ Received 9 Januari2017 \\ Revised 10 Januari 2017 \\ Accepted 12 Januari 2017 \\ Available online $12 \mathrm{Mei}$ \\ 2017}

\section{Keywords:}

Career Development,

Job Satisfaction,

Social Work Environment

\section{Kata Kunci:}

Kepuasan Kerja Karyawan, Lingkungan Kerja Sosial, Pengembangan Karir

\section{PENDAHULUAN}

Masalah kepuasan kerja karyawan saat ini masih menjadi isu yang sangat penting dalam berbagai sektor industri. Kepuasan kerja karyawan mengacu pada kepuasan karyawan dengan pekerjaannya. Ini berarti pemenuhan keinginan dan kebutuhan karyawan harus menjadi perhatian serius, (Kiruthiga V dan R. Magesh, 2015). Karyawan adalah tulang punggung setiap organisasi, tanpa karyawan tidak ada pekerjaan yang bisa dilakukan. Jadi kepuasan karyawan dalam sebuah organisasi menjadi hal penting untuk diperhatikan, (Vrinda dan Nisha Ann Jacob, 2015; Malik et al, 2012; Zahid Noor, 2015).
Kepuasan karyawan merupakan salah satu faktor penentu keberhasilan suatu perusahaan. Karyawan yang merasa puas akan menunjukkan loyalitasnya dan mampu bekerja dengan efektif. Hal ini merupakan tantangan bagi perusahan untuk tetap menjaga loyalitas karyawan dan memotivasi karyawan agar karyawan menunjukkan kinerja yang optimal sehingga tujuan perusahaan akan tercapai sesuai dengan harapan. (Muhammad Ibrar etl al., 2015; Jitendra Kumar Singh, 2013; Akmal Umar, 2014; Alam Sageer et al., 2012).

Indonesia merupakan negara yang memiliki berbagai macam sektor industri salah 


\section{N. Maharani, Sumiyati \& Masharyono., \\ LINGKUNGAN KERJA SOSIAL DAN PENGEMBANGAN KARIR SEBAGAI PENGARUH \\ KEPUASAN KERJA KARYAWAN}

| 16

satunya yaitu industri manufaktur. Tahun 2015 Indonesia masuk ke dalam 15 negara dengan aktivitas industri manufaktur terbesar. Namun prestasi tersebut tidak berbanding lurus dengan fakta bahwa sebesar 73\% karyawan di Indonesia tidak merasa puas dengan pekerjaannya. Hasil survey JobsDB Indonesia menyebutkan alasan terbanyak adalah masalah gaji, fasilitas, jenjang karir dan minimnya program pengembangan karir. Industri manufaktur tersebar di beberapa wilayah di Indonesia tidak terkecuali di Jawa Barat. (www.bisnis.liputan6.com. Akses: 04:25 WIB. Selasa, 4 Oktober 2016).

Salah satu perusahaan yang bergerak dalam industri manufaktur yang beroperasi di wilayah Jawa Barat yaitu PT.Sung Chang yang mengalami permasalahan kepuasan kerja selama 4 tahun terakhir. PT Shung Chang berlokasi di Jl, Husen Kartasasmita No. 212 Kota Banjar. Perusahaan ini merupakan perusahaan asing yang bergerak di bidang pembuatan bulu mata palsu dan rambut palsu (WIG) yang dipasarkan di dalam negeri dan ekspor ke berbagai negara seperti AS, Kanada dan Prancis.

Hasil penelitian terdahulu yang dilakukan oleh Mobley, Horner dan Hollingworth dalam Munandar (2002:336) yang menunjukkan bukti bahwa kepuasan kerja berkorelasi dengan pemikiran seseorang untuk meninggalkan pekerjaan. Menurut Usman (2011:497) faktorfaktor yang mempengaruhi kepusan kerja yaitu: 1) imbalan jasa, 2) rasa aman, 3) pengaruh antar pribadi, 4) kondisi lingkungan kerja dan 5) kesempatan untuk pengembangan dan peningkatan diri.

Berdasarkan pernyataan di atas salah satu faktor yang mempengaruhi kepuasan kerja karyawan adalah kondisi lingkungan kerja. Menurut Schultz dan Schultz dalam Mangkunegera (2010:105) mengemukakan kondisi lingkungan kerja yang dapat mempengaruhi karyawan dalam bekerja, yakni baik dari segi lingkungan fisik maupun lingkungan kerja non fisik yang meliputi lingkungan kerja temporer yaitu terdiri dari jumlah waktu jam bekerja dan waktu istirahat kerja serta lingkungan kerja psikologis yang terdiri dari kebosanan, pekerjaan yang monoton dan keletihan.

Salah satu faktor yang mempengaruhi kepuasan kerja karyawan adalah lingkungan kerja sosial. Lingkungan kerja sosial mencakup hubungan yang terbina dalam perusahaan, dalam hal ini lingkungan kerja sosial adalah lingkungan kerja yang tidak dapat ditagkap dengan panca indera manusia. Akan tetapi, lingkungan kerja sosial ini dapat dirasakan oleh para pekerja melalui hubungan sesame pekerja maupun dengan atasan. Penelitian Elton Mayo (1950) mengemukakan In an enterprise employees tend to form informal groups can provide job satisfaction an effectiveness. Hasil penelitian yang dilakukan oleh Amasusri Nasution (2013) menunjukkan bahwa rlingkungan kerja sosial yang mendukung maka karyawan akan merasa nyaman dan karyawan akan merasa puas berada di lingkungan kerja sehingga menunjukkan kinerja yang baik dan diharapkan dapat meningkatkan perkembangan perusahaan.

Selanjutnya faktor lain yang mempengaruhi kepuasan kerja yaitu kesempatan untuk pengembangan dan peningkatan diri dalam hal ini berkaitan dengan masa depan karir karyawan dalam perusahaan tersebut. Penelitian yang dilakukan oleh Pradnya (2011) mengemukakan bahwa kepuasan dalam konteks karir tidak hanya mencapai posisi tinggi dalam organisasi,namun kenaikan jabatan merupakan salah satu contoh apresiasi perusahaan terhadap para karyawan. Oleh karena itu pengembangan karir merupakan salah satu faktor penting dalam organisasi khususnya untuk mendorong para karyawan memenuhi tujuan organisasi sehingga tercapai kepuasan kerja yang baik.

Tujuan penelitian ini adalah untuk memperoleh temuan mengenai (1) Gambaran lingkungan kerja sosial di PT.Sung Chang. (2) Gambaran pengembangan karir karyawan di PT.Sung Chang, (3) Gambaran kepuasan kerja karyawan di PT.Sung Chang (4) Pengaruh lingkungan kerja sosial terhadap kepuasan kerja pada karyawan PT.Sung Chang, (5) Pengaruh pengembangan karir terhadap kepuasan kerja 
pada karyawan PT.Sung Chang, (6) Pengaruh lingkungan kerja sosial dan pengembangan karir terhadap kepuasan kerja karyawan di PT. Sung Chang.

Kinerja sumber daya manusia secara langsung atau tidak langsung memberikan kontribusi terhadap kemajuan suatu negara. Maju mundurnya suatu negara dapat dilihat dari perkembangan dan kualitas sumber daya manusianya. Berdasarkan penilaian HDI, kedudukan Indonesia masih dibawah rata-rata indeks pembangunan manusia dunia 0,694 dan regional 0,683. Belum optimalnya kinerja karyawan sangat dirasakan oleh beberapa perusahaan milik Negara Indonesia, namun hal ini tidak menyurutkan niat bagi sebagian besar perusahaan pada umumnya untuk tetap tumbuh dan terus berkembang dan khususnya pada perusahaan BUMN Perkebunan yaitu PT. Perkebunan Nusantara VIII.

Salah satu hambatan dalam meningkatkan kinerja perusahaan adalah ketidakhadiran atau pergantian karyawan yang tinggi sehingga perusahaan perlu menindaklanjuti hal tersebut agar kinerja karyawan kembali meningkat Benardin dan Russel dalam (Kaswan, 2012:205). Hunt et. al (2010:391) Kinerja dikaitkan dengan konsep kemampuan karena untuk perbaikan dalam meningkatkan kualitas yang terbaik. Kemampuan tersebut merupakan kapasitas seseorang didalam mengerjakan berbagai macam tugas dalam pekerjaannya. Steers dalam Sutrisno (2014:151), umumnya orang percaya bahwa prestasi atau kinerja kerja individu merupakan fungsi gabungan dari tiga faktor, yaitu: (1) kemampuan (kompetensi) dan minat bekerja seseorang, (2) kejelasan dan penerimaan atas penjelasan peranan seorang pekerja, (3) tingkat motivasi kerja. Motivasi adalah suatu dorongan kehendak yang dapat menyebabkan seseorang melakukan suatu perbuatan untuk mencapai tujuan tertentu.

Organisasi membutuhkan sumber daya manusia yang dapat bekerja efisien dan efektif dan organisasi harus mampu melakukan pengelolaan karyawan dengan baik (Masharyono, Pratama, dan Purnama, 2016). Kinerja karyawan yang efektif menjadi penting untuk terus ditingkatkan demi membantu organisasi guna mencapai tujuan bisnisnya (Reymon A. Noe, 2011:226).

Rivai dan Jauvani,

mengungkapkan bahwa motivasi dapat memacu karyawan untuk bekerja keras sehingga dapat mencapai tujuan mereka. Hal ini akan meningkatkan kinerja. karyawan sehingga berpengaruh pada pencapaian tujuan perusahaan. Murty dan Hudiwinarsih (2012) menyatakan bahwa seorang karyawan yang termotivasi akan bersifat energik dan bersemangat, dan sebaliknya seorang karyawan dengan motivasi yang rendah akan sering menampilkan rasa tidak nyaman dan tidak senang terhadap pekerjaannya yang mengakibatkan kinerja mereka menjadi buruk dan tujuan perusahaan tidak akan tercapai.

Berdasarkan pemaparan di atas, dapat dikatakan bahwa rendahnya kinerja karyawan pada suatu perusahaan berkaitan dengan faktor kompetensi dan motivasi kerja. Sehingga kinerja karyawan perlu tingkatkan, agar tidak menghambat pencapaian tujuan perusahaan. Adapun penelitian ini bertujuan untuk memperoleh (1) gambaran kompetensi, (2) gambaran motivasi kerja, (3) gambaran kinerja karyawan, (4) pengaruh kompetensi terhadap kinerja karyawan, (5) pengaruh motivasi kerja terhadap kinerja karyawan, dan (6) pengaruh kompetensi dan motivasi kerja terhadap kinerja karyawan.

lingkungan kerja sebagai salah satu fungsi penunjang kepuasan kerja karyawan. Karyawan yang merasa puas ditempatnya bekerja akan memberikan loyalitasnya bagi perusahaan dan menunjukkan kinerja yang optimal. Kedudukan lingkungan kerja terletak pada fungsi pengarahan. Dimana dalam fungsi pengarahan ini mencakup motivasi dua arah. Motivasi dua arah menurut Stephen P. Robbins dan Mary Coutler (2012) meliputi dua faktor yaitu faktor motivasional dan faktor Hygine. Lingkungan kerja termasuk ke dalam faktor hygine.

Adapun faktor-faktor hygine terdiri dari kebijakan perusahaan, supervisi, hubungan dengan supervisor, kondisi lingkungan kerja, gaji, hubungan dengan teman sebaya, kehidupan 


\section{N. Maharani, Sumiyati \& Masharyono., \\ LINGKUNGAN KERJA SOSIAL DAN PENGEMBANGAN KARIR SEBAGAI PENGARUH \\ KEPUASAN KERJA KARYAWAN}

| 18

pribadi, hubungan dengan bawahan, status dan keamanan (Miftah Thoha; 2012:230-232). Menurut Sedarmayanti (2011:26) Lingkungan kerja adalah keseluruhan alat perkakas dan bahan yang dihadapi, lingkungan sekitarnya dimana seorang bekerja, metode kerjanya, serta pengaturan kerjanya baik sebagai perseorangan maupun sebagai kelompok.

Selanjutnya faktor lain yang dapat mempengaruhi kepuasan kerja karyawan yaitu program pengembangan karir. Kedudukan pengembangan karir terletak pada fungsi pengembangan dalam manajemen sumber daya manusia. Gary Dessler (2009:5) mengemukakan bahwa pengembangan SDM diwujudkan melalui manajemen karir, pengembangan karir dan perencanaan karir. Pengembangan karir merupakan serangkaian aktivitas sepanjang hidup (seperti workshop) yang berkontribusi pada eksplorasi, pemantapan, keberhasilan dan pencapaian karir seseorang.

\section{KAJIAN PUSTAKA}

Manajemen sumber daya manusia menurut Mathis \& Jackson (2012:5) sebagai ilmu dan seni yang mengatur hubungan dan peranan tenaga kerja agar efektif dan efisien dalam penggunaan kemampuan manusia agar dapat mencapai tujuan di setiap perusahaan. Sedangkan Menurut I Komang Ardana, dkk (2012:5) manajemen sumber daya manusia adalah suatu proses pemanfaatan sumber daya manusia secara efisien melalui kegaiatan perencanaan, penggerakan, dan pengendalian semua nilai yang menjadi kekuatan manusia untuk mencapai tujuan. Tujuan utama manajemen sumber daya manusia adalah memperbaiki tingkat produktivitas, memperbaiki kualitas kehidupan kerja, meyakinkan organisai telah memenuhi aspekaspek legal (Schuler dalam Edy Sutrisno. 2010:8).

Menurut Amstrong (2010:9) "The overall purpose of HRM (or people management) is to ensure that the organization is able to achieve success through people". Tujuan keseluruhan dari manajemen sumber daya manusia adalah untuk memastikan bahwa organisasi mampu mencapai keberhasilan melalui sumber daya manusia yang dimilikinya.

\section{Konsep Lingkungan Kerja Sosial}

Lingkungan kerja adalah keseluruhan sarana dan prasarana yang ada disekitar pegawai yang sedang melakukan pekerjaan yang dapat mempengaruhi pelaksanaan pekerjaan itu sendiri. (Gouzaly Saydam,2010:226). Menurut Joan E Paynes (2009:136) "The work environment is supportive and nurturing and contribution are appreciated". Selain lingkungan iintern perusahaan yang menjadi pusat perhatian, seorang manajer harus juga menyadari pentingnya pengaruh lingkungan eksternal perusahaan dengan mempertimbangkan unsur-unsur dan kekuatan lingkungan eksternal dalam setiap kegiatannya yang sangat berpengaruh dalam perusahaan. (Alex S. Nitisemito dalam Kevin, 2016:12).

Lingkungan kerja sosial adalah semua keadaan yang terjadi yang berkaitan dengan hubungan kerja,baik hubungan dengan atasan maupun dengan sesama rekan kerja, ataupun hubungan dengan bawahan. Selain itu menurut Soehardi (2003:183) mengemukakan Lingkungan kerja sosial sangat berpengaruh tehadap kerja pekerja adalah latar belakang keluarga pekerja. Pada pekerja perusahaan jasa, faktor psikologis yang berupa beban sosial sangat berpengaruh terhadap kepuasan kerjanya dan masuk dalam pertimbangan perencanaan lingkungan kerja. Menurut Sutermeister (1976:57) dalam Syamsul Hadi Senen (2009:26) mengemukakan "The Major factor which establish the social condition in an organization are considered to be formal organization, informal organization or groups, leaders and supervisors and the union" 


\section{Konsep Pengembangan Karir}

Pengembangan karir merupakan bagian dari tanggung jawab perusahaan guna menyiapkan karyawan agar memiliki kualifikasi tertentu yang dapat menunjang kinerjanya sesuai dengan harapan perusahaan.Menurut Kadarisman (2012:322). Sedangkan Menurut Garry Dessler (2009:5). Pengembangan karir karyawan adalah proses dan kegiatan mempersiapkan seorang karyawan untuk menduduki jabatan dalam organisasi atau perusahaan, yang akan dilakukan dimasa mendatang. Pengembangan karir merupakan serangkaian aktivitas sepanjang hidup (seperti workshop) yang berkontribusi pada eksplorasi, pemantapan, keberhasilan dan pencapaian karir seseorang. Sementara Gary Dessler (2009:8) mengemukakan dimensi pengembangan karir terdiri dari 1) Tanggung jawab karir, 2) Keahlian, 3) Informasi Karir, 4) Perencanaan karir dan 5) Kesempatan Pengembangan.

$$
\text { Soekidjo Notoatmodjo }
$$
mengemukakan tujuan dari pengembangan karir antara lain sebagai berikut: meningkatkan kesadaran perlunya klasifikasi tugas atau pekerjaan., merupakan masukan untuk perencanaan program pengembangan organisasi. membantu karyawan menyusun strategi pengembangan. Selektif untuk mengikuti program-program pengembangan., mempermudah pemanfaatan potensi karyawan, mempermudah meningkatkan motivasi karyawan, mempermudah proses promosi karyawan, mempermudah peningkatan kepuasan kerja., mengurangi turnover dan meningkat loyalitas karyawan.

\section{Konsep Kepuasan Kerja Karyawan}

Menurut Stephen P. Robbins dan Timothy A. Judge (2013:374) berpendapat bahwa kepuasan kerja mengacu pada sikap umum seorang karyawan terhadap pekerjaannya. Meskipun kepuasan kerja adalah sikap daripada perilaku, itu adalah hasil yang menyangkut banyak manajer karena karyawan puas lebih mungkin untuk masuk kerja, memiliki tingkat yang lebih tinggi kinerja dan tingga bersama sebuah organisasi. Disamping itu Edy Sutrisno (2014:75) menyatakan pada hakikatnya, kepuasan kerja merupakan perasaan senang atau tidak senang pekerjaan dalam memandang dan menjalankan pekerjaanya. Apabila seseorang senang terhadap pekerjaannya, maka orang tersebut puas terhadap pekerjaannya.

Senada dengan pendapat Wibowo (2013:374) menjelaskan bahwa kepuasan kerja merupakan tingkat perasaan senag seseorang sebagai penilaian positif terhdap pekerjaannya dan lingkungan tempat pekerjaannya. Dimensi kepuasan kerja yang akan dikaji dalam penelitian ini adalah dimensi kepuasan menurut Sedangkan indikator kepuasan kerja menurut Chr. Jimmy L. Gaol (2014:243) yaitu: 1. The work it self (pekerjaan itu sendiri), 2. Pay (bayaran), 3. Promotion (promosi), 4. Supervision (supervisi) dan 5, Co-worker (rekan kerja).

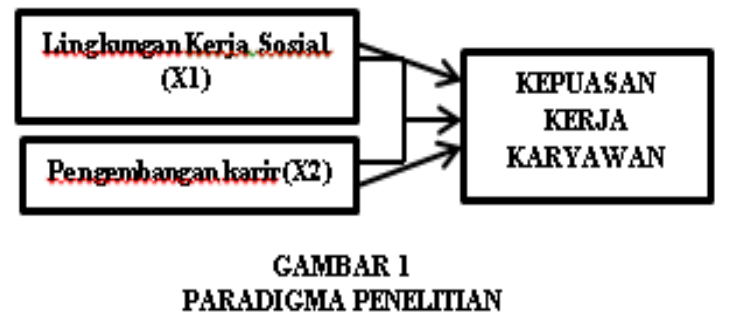

\section{METODE PENELITIAN}

Penelitian ini dilakukan untuk mengetahui pengaruh pembelajaran kewirausahaan terhadap rasa percaya diri serta implikasinya terhadap motif berwirausaha. Variabel X1 adalah Lingkungan kerja sosial dengan dimensinya kepemimpinan, serikat kerja, organisasi formal dan organisasi informal. Variabel X2 dengan dimensinya tanggung jawab karir, keahlian, informasi karir, perencanaan karir dan kesempatan pengembangan. Sementara variabel $\mathrm{Y}$ adalah kepuasan kerja karyawan dengan dimesi yang terdiri dari The work it self (pekerjaan itu sendiri), Pay (bayaran), Promotion (promosi), Supervision (supervisi) dan Co-worker (rekan kerja).

Penelitian ini dilakukan pada kurun waktu kurang dari satu tahun, sehingga teknik pengumpulan data yang digunakan pada 


\section{N. Maharani, Sumiyati \& Masharyono., \\ LINGKUNGAN KERJA SOSIAL DAN PENGEMBANGAN KARIR SEBAGAI PENGARUH \\ KEPUASAN KERJA KARYAWAN}

penelitian ini adalah cross-sectional method. Teknik yang digunakan dalam penelitian ini adalah teknik propability yaitu simple random dengan jumlah sampel sebanyak 102 responden. Teknik pengumpulan data yang digunakan adalah studi kepustakaan, studi lapangan dengan penyebaran kuesioner, dan studi literatur. Sedangkan teknik analisis data yang dilakukan adalah analisis deskriptif dan verifikatif. Analisis data verifikatif menggunakan regresi linier berganda dengan bantuan software SPSS 21.0 for windows.

\section{HASIL PENELITIAN DAN PEMBAHASAN}

Berdasarkan rekapitulasi tanggapan responden pada aspek lingkungan kerja sosial paling tinggi yaitu terdapat pada dimensi Informal Organization (organisasi informal) memperoleh skor sebanyak 1060 atau 74,23\%, sementara dimensi paling rendah yaitu pada Union (serikat kerja) memperoleh skor 1562 atau $72,92 \%$. Secara keseluruhan variabel lingkungan kerja sosial memperoleh skor 8762, dapat dikatakan seluruh responden menyatakan lingkungan kerja sosial pada pemimpin Bank PT. Sung Chang Cabang Kota Banjar dalam kategori kondusif. Selanjutnya Berdasarkan hasil penelitian dari kuesioner yang disebar kepada 102 responden diketahui bahwa pengembangan karir karyawan mencapai skor 7667 dari skor kriterium atau jumlah maksimal perolehan nilai responden yang terletak pada daerah kriterium cukup baik yaitu pada interval 6775.7-8087.1.

Berdasarkan hasil penelitian dari kuesioner yang disebar kepada 80 responden diketahui bahwa kepuasan kerja karyawan PT. Sung Chang mencapai skor 9175 dari skor kriterium atau jumlah maksimal perolehan nilai responden yang terletak pada daerah kriterium sangat tinggi yaitu pada interval 9165.410651.7. Dalam penelitian ini dapat disimpulkan bahwa kepuasan kerja karyawan Bagian Produksi PTSung Chang telah terpenuhi dengan baik, akan tetapi kepuasan kerja tersebut masih perlu ditingkatkan lagi, karena semua dimensi berada di bawah skor ideal.

\section{KESIMPULAN DAN REKOMENDASI}

Berdasarkan penelitian di atas menyatakan bahwa lingkungan kerja sosial PT. Sung Chang berada pada kategori kondusif. Hal ini dapat dilihat dari dimensi yang mendapat skor tertinggi dan terendah. Gambaran mengenai lingkungan kerja sosial PT. Sung Chang dapat dilihat dari dimensinya yang terdiri dari: 1) kepemimpinan (leaderdhip), 2) serikat kerja (union), 3) organisasi formal (formal organization) dan 4) organisasi informasl (informal organization). Dimensi organisasi informal (informal organization) merupakan dimensi yang memiliki skor/penilaian paling tinggi, sedangkan dimensi serikat kerja (union) merupakam dimensi yang memiliki penilaian paling rendah. Hal ini disebabkan karena karyawan merasa bahwa tidak semua permasalahan karyawan dapat diselesaikan melalui serikat kerja.

Berdasarkan penelitian di atas menyatakan bahwa pengembangan karir karyawan PT. sung Chang berada pada kategori cukup baik. Hal ini dapat dilihat dari dimensi yang mendapat skor tertinggi dan terendah. . Gambaran mengenai pengembangan karir PT. Sung Chang dapat dilihat dari dimensinya yang terdiri dari: 1) tanggungjawab karir, 2) keahlian, 3) informasi karir, 4) perencanaan karir dan 5) kesempatan pengembangan. Dimensi informasi karir merupakan dimensi yang memiliki skor/penilaian paling tinggi, sedangkan dimensi tanggungjawab karir merupakam dimensi yang memiliki penilaian paling rendah. Program pengembangan karir yang dilaksanakan pada PT. Sung Chang masih memiliki beberapa kelemahan, hal tersebut terliht dari kuranganya tanggungjawab karyawan dalam bekerja. Karyawan sering mengalami keterlambatan dalam penyelesaian tugasnya (deadline) dan karyawan belum sepenuhnya mampu menyelesaikan pekerjaan sesuai dengan standar perusahaan. 
DAFTAR PUSTAKA

Amstrong, Michael. 2010. Armstrong's Handbook Of Human Resorce Management Practice $11^{\text {th }}$ Edition. United Kingdom: Kogan Page Limited.

Ardana, I Komang, Dkk. 2012. Manajemen Sumber Daya Manusia. Yogyakarta: Graha Ilmu.

Chr. Jimmy L. Gaol. 2014. A To Z Human Capital. Jakarta: Gramedia Widiasarana Indonesia.

Dessler, Gary. 2009. A Framework For Human Resource Management. Pearson Pretice Hall: New Jersey.

Ibrar, Muhammad, Owais Khan. 2015. The Impact Of Reward On Employee Performance.International Letters Of Social And Humanistic Sciences, Vol 52,Pp 95-103

Kiruthiga, V, R. Magesh. 2015. Gravity Of Job Based Determinants Among Different Levels Of Star Category Hotel Employee.Australian Journal Of Basic And Applied Sciences, 9 (10), Pp:226272.

Malik, Muhammad Ehsan Et Al. 2012. The Impact Of Pay And Promotion On Job Satisfaction: Evedence From Higer Education Institute of Pakistan. American Journal Of Economics. Pp:6-9

Mangkunegara, A.Anwar Prabu. 2013. Manajemen Sumber Daya Manusia Perusahaan. Bandung: Pt. Refika Aditama.

Malthis, Robert L Dan Jackson, John A. 2012. Manajemen Sumber Daya Manusia. Jakarta: Salemba Empat.
Miftah Thoha. 2012. Perilaku Organisasi: Konsep Dasar Dan Aplikasinya. Jakarta: Rajawali Pers.

Mondy, R W \& Noe R M. 2005. Human Resources Management $\left(9^{\text {th }} \quad E d\right)$. Massachusetts: Person Education, Inc.

Rivai, Veithzal Dan Ella Jauvani. 2010. Manajemen Sumber Daya Manusia Untuk Perusahaan Dari Teori Ke Praktik. Jakarta: Pt Raja Grafindo.

Nitisemito, Alex S. 2009. Manajemen Personalia. Edisi Kedua. Jakarta:Ghalia Indonesia.

Senen, Syamsul Hadi. (2009). Pengaruh Kondisi Sosial, Kondisi Fisik, Kebutuhan Individu Dan Kemampuan Kerja Terhadap Kinerja Pelayanan Serta Implikasinya Terhadap Kepuasan Kerja Pegawai. [Disertasi]. Universitas Padjadjaran.

Sutrisno, Edy. 2014. Manajemen Sumber Daya Manusia. Jakarta: Prenada Media.

Robbins, Stephen P. Dan Timothy A. Judge. 2013. Organizational Behavior $15^{\text {th }}$ Edition. Prentice Hall: Pearson Education, Inc.

Robbins, Stephen P. Dan Mary Coulter. 2012. Management $11^{\text {th }}$ Edition. New Jersey: Pearson Education, Inc.

Sedarmayanti. 2009. Manajemen Sumber Daya Manusia Reformasi Birokrasi Dan Manajemen Pegawai Negeri Sipil. Bandung: Pt. Refika Aditama 